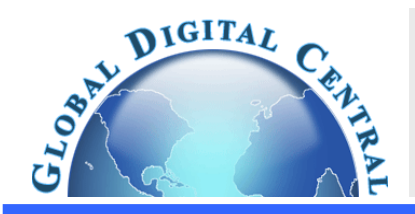

Frontiers in Heat and Mass Transfer

Available at www.ThermalFluidsCentral.org

\title{
MAGNETOHYDRODYNAMIC(MHD) STAGNATION POINT FLOW AND HEAT TRANSFER OF UPPER-CONVECTED MAXWELL FLUID PAST A STRETCHING SHEET IN THE PRESENCE OF NANOPARTICLES WITH CONVECTIVE HEATING
}

\author{
Wubshet Ibrahim* \\ Department of Mathematics, Ambo University, Ambo, P.O.Box 19, Ambo, Ethiopia
}

\begin{abstract}
The study scrutinizes the effect of convective heating on magnetohydrodynamic (MHD) stagnation point flow and heat transfer of upper-convected Maxell fluid $\mathrm{p}$ ast a s tretching s heet in the presence of $\mathrm{n}$ anoparticles. The m odel $\mathrm{u}$ sed in the $\mathrm{s}$ tudy i ncludes the e ffect of $\mathrm{B}$ rownian $\mathrm{m}$ otion and thermophoresis parameters. The non-linear governing equations and their boundary conditions are initially cast into dimensionless forms by similarity transformation. The resulting system of equations is then solved numerically using fourth order Runge-Kutta method along with shooting technique. Numerical results are obtained for velocity, temperature, concentration profiles, skin friction coefficient, local Nusselt number and Sherwood number. It is found that the skin friction coefficient, the local Nusselt number and Sherwood number increase with an increase in A and $\beta$ and decreases as the values of M increase. Moreover, the local Nusselt number $-\theta^{\prime}(0)$ and local Sherwood number - $\phi^{\prime}(0)$ increases with an increase in Bi.

keywords: Nanofluid; MHD; Stagnation point flow; Heat transfer; Convective boundary condition; upper-convected Maxwell fluid
\end{abstract}

\section{INTRODUCTION}

The increasing demand of non-Newtonian fluids in many industries has aroused a strong motivation to study their behavior in several transport processes. The studies of boundary layer flow and heat transfer of nonnewtonian fluids over stretching surface have received considerable attention due to their many theoretical and technical applications in the engineering and technology. Few examples of such applications are drilling mud, plastic polymers, optical fibers etc. and many more. The knowledge of heat transfer of non-Newtonian fluids over a stretching sheet is crucial in understanding the coating process and the design of various heat exchangers and chemical-processing equipment. The comprehensive review of literature on boundary layer flow and heat transfer of nonNewtonian fluids are given in the references Hady et al. (2011); Abel et al. (2012); Hsiao (2011); Mahapatra and Gupta (2002); Hayat et al. (2012b); Kumari et al. (2010).

Due to viscosity difference in fluids, researchers proposed different models to study non-Newtonian fluids which accommodate all the features of non-Newtonian materials. Theses models are classified into three categories. They are differential, rate and integral type fluids. The fluid model under consideration is subclass of a rate type fluid called Maxwell fluids. This fluid model predicts the relaxation time effect. The upperconvected Maxwell (UCM) model is a generalization of the Maxwell material for the case of large deformations using the upper-convected time derivative.

Generally, the flow of Maxwell fluid has been studied by many researchers. Accordingly, Rajagopal (2012) gave the generalized classical viscoelastic fluid due to Maxwell to allow the relaxation time. Moreover, Abel et al. (2008) numerically investigated the MHD flow and heat transfer of the upper convected Maxwell fluid past a stretching sheet. Similarly, Kumari and Nath (2009) analyzed numerically steady mixed convection stagnation point flow of upper-convected Maxwell fluids with induced magnetic field. Their study shows that the surface velocity gradient and heat transfer are increased by increasing magnetic and buoyancy parameter. Sadeghy et al. (2005) studied the Sakiadis flow of an upper-convected Maxwell fluid. The analysis indicated that the wall skin friction coefficient is predicted to decrease with an increase in the Deborah number for Sakiadis flow of a upper-convected Maxwell (UCM) fluid. This prediction is indirect contradiction with the reports in the literature for a second-grade fluid. Furthermore, Sadeghy et al. (2006) studied stagnation point flow of upper-convected Maxwell fluids. Still further, Hayat et al. (2009) extended the study of Maxwell fluid and analyzed MHD stagnation-point flow of an upper-convected Maxwell fluid over a stretching surface. Their study shows that the magnitude of the skin-friction coefficient increases for large values of Deborah number $\beta$. Similarly, Hayat et al. (2012a) analyzed melting heat transfer in the stag-

$\dagger^{\dagger}$ author.Email:wubshetib@yahoo.com 
nation point flow of an upper-convected Maxwell fluids past a stretching/shrinking sheet. The study indicated that velocity field is a decreasing function of Deborah number. The boundary layer flow of the upper convected Maxwell fluid was investigated by Renardy and Wang (2012). Moreover, Hayat et al. (2011) studied the effects of mass transfer on the two-dimensional stagnation point flow of an upper-convected Maxwell (UCM) fluid over a stretching surface. Their analysis indicated that the effects of magnetic field and Deborah number $\beta$ on velocity and concentration $\phi$ are quite opposite. Still further, Hayat and Qasim (2010) and Aliakbar et al. (2009) investigated the effect of thermal radiation and joule heating on MHD flow of a Maxwell fluid over a stretching sheet in the presence of thermophoresis. Their analysis indicated that the magnitude of the local Nusselt and Sherwood number increases when porosity parameter $\lambda$ is increased. Furthermore, Hayat et al. (2008) investigated MHD flow and mass transfer of a upper-convected Maxwell fluid past a porous shrinking sheet with chemical reaction species.

Motsa et al. (2012) studied MHD flow of upper-convected Maxwell fluid over porous stretching sheet using successive Taylor series linearization method. The numerical result shows that in the presence of suction, the effect of an increase in the elasticity parameter $\beta$ is to reduce the flow velocity and decrease the skin friction at the stretching surface. The opposite effect is observed in the presence of injection. Similarly, Alizadeh-Pahlavan et al. (2009) investigated MHD flows of UCM fluids above porous stretching sheets using two-auxiliary-parameter homotopy analysis method. Their numerical results indicated that an increase in the elasticity or magnetic number, the wall shear stress represented by $f^{\prime \prime}(0)$ is increased and the boundary layer thickness is decreased.

Moreover, the study of slip, magnetohydrodynamic stagnation point flow and heat transfer of a power-law fluid towards a stretching sheet has been discussed by investigators Mahapatra et al. (2009); Khan and Gorla (2012).

Recently, the study of heat transfer under convective boundary condition received numerous interests on the researchers side due to its influence on heat transfer characteristics on the surface and consequently, the quality of the final product of the manufacturing industries. The study of a convective heat transfer in magnetic field is important in processes, such as, gas turbine, nuclear plants, thermal energy storage, etc. Since then, different researchers extended the idea of convective heating to various configurations of the flat plate and stretching sheet. Accordingly, researchers in the references Aziz (2009, 2010); Ishak et al. (2011); Bataller (2008); Yao et al. (2011); Ishak (2010); Merkin and Pop (2011); Makinde and Olanrewaju (2010) studied the heat transfer under convective boundary condition over a flat surface.

Furthermore, Ibrahim and Shanker (2012) have numerically examined the boundary-layer flow and heat transfer of Nanofluid over a vertical plate with convective surface boundary condition. Their study indicated that the local Nusselt number and Sherwood number increase with an increase in convective parameter and Lewis number.

Also, Vajravelu et al. (2011) have discussed the convective heat transfer in a nanofluid flow over a stretching surface by focusing on Agwater and $\mathrm{Cu}$-water nanofluid. They have investigated the effects of the nanoparticle volume fraction on the flow and heat transfer characteristics under the influence of thermal buoyancy and temperature dependent internal heat generation or absorption. Their numerical result indicates that an increase in the nanoparticle volume fraction will decrease the velocity boundary layer thickness while increasing the thermal boundary layer thickness.

Moreover, Mustafa et al. (2011) and Bachok et al. (2010) have studied the stagnation point flow and heat transfer characteristic of a nanofluid over a stretching sheet. Their findings show that the highest value of heat transfer was obtained for $\mathrm{Cu}$ nanoparticle near the nodal point. Furthermore, Ibrahim et al. (2013) investigated the MHD stagnation point flow and heat transfer due to nanofluid towards a stretching sheet numerically. Their analysis indicates that an increase in velocity ratio parameter A increases both the local Nusslet number and local Sherwood number. Recently, Ibrahim and Shankar (2013) have analyzed MHD boundary layer flow and heat transfer of a nanofluid past a permeable stretching sheet with velocity, thermal and solutal slip boundary conditions. Very recently, Ibrahim and Makinde (2013) studied the effect of double stratification on boundary layer flow and heat transfer of nanofluid over a vertical plate.

All the above investigators ignore the effects of nanoparticles in the analysis of the problem of Maxwell fluid.

In view of this, the present paper aim to analyze the effect of nanoparticle and convective heating on MHD stagnation point flow, the boundary layer flow and heat transfer of upper-convected Maxwell fluid over a stretching sheet using Runge-Kutta fourth order with shooting technique. Therefore, the inclusion of the effect of nanoparticles makes this study a novel one. The effects of governing parameters on fluid velocity, temperature and particle concentration have been discussed and shown graphically and in tables. The results are compared with the results available in the open literature and are found to be in an excellent agreement.

\section{MATHEMATICAL FORMULATION}

Consider a two-dimensional steady state MHD stagnation point flow of upper-convected Maxwell fluid past stretching sheet in the presence of nanoparticles subjected to a convective heating process at its lower surface, which is characterized by a temperature $T_{f}$ and a heat transfer coefficient $h_{f}$. The coordinate system such that the $\mathrm{x}$-axis is along the sheet and y-axis is normal to the sheet is chosen for this study. At this boundary, concentration $\mathrm{C}$ take constant values $C_{w}$. The ambient values attained as y tends to infinity of $\mathrm{T}$ and $\mathrm{C}$ are denoted by $T_{\infty}$ and $C_{\infty}$, respectively. The free stream velocity distribution is assumed to be in the form $u_{\infty}=b x$ and $u_{w}=a x$ is the velocity of the stretching sheet, where a and $\mathrm{b}$ are positive constants. $\lambda$ is the relaxation time parameter of the fluid. $B_{0}$ is the strength of the magnetic field, $v$ is the kinematic viscosity of the fluid. Under these assumptions, along with the boundary-layer approximations, the governing equation of mass, momentum, thermal energy and concentration of steady, laminar boundary-layer flow of a nanofluid past a stretching sheet is given by Abel et al. (2012) as:

$$
\begin{aligned}
\frac{\partial u}{\partial x}+\frac{\partial v}{\partial y} & =0 \\
u \frac{\partial u}{\partial x}+v \frac{\partial u}{\partial y} & =-\lambda\left(u^{2} \frac{\partial^{2} u}{\partial x^{2}}+v^{2} \frac{\partial^{2} u}{\partial y^{2}}+2 u v \frac{\partial^{2} u}{\partial x \partial y}\right) \\
& +v \frac{\partial^{2} u}{\partial y^{2}}+U_{\infty} \frac{\partial U_{\infty}}{\partial x}+\frac{\sigma B_{0}^{2}}{\rho_{f}}\left(U_{\infty}-u\right) \\
u \frac{\partial T}{\partial x}+v \frac{\partial T}{\partial y} & =\alpha \frac{\partial^{2} T}{\partial y^{2}}+\tau\left\{D_{B} \frac{\partial C}{\partial y} \frac{\partial T}{\partial y}+\frac{D_{T}}{T_{\infty}}\left(\frac{\partial T}{\partial y}\right)^{2}\right\} \\
u \frac{\partial C}{\partial x}+v \frac{\partial C}{\partial y} & =D_{B} \frac{\partial^{2} C}{\partial y^{2}}+\frac{D_{T}}{T_{\infty}} \frac{\partial^{2} T}{\partial y^{2}}
\end{aligned}
$$

Where $\alpha=\frac{k}{(\rho c)_{f}}, \tau=\frac{(\rho c)_{p}}{(\rho c)_{f}}$

The boundary conditions are:

$$
\left.\begin{array}{l}
u=u_{w}=a x, \quad v=0, \quad-k \frac{\partial T}{\partial y}=h_{f}\left(T_{f}-T\right), \quad C=C_{w} \quad \text { at } \quad y=0 \\
u \rightarrow U_{\infty}=b x, \quad v=0, \quad T \rightarrow T_{\infty}, \quad C \rightarrow C_{\infty} \quad \text { as } \quad y \rightarrow \infty
\end{array}\right\}
$$$$
u \rightarrow U_{\infty}=b x, \quad v=0, \quad T \rightarrow T_{\infty}, \quad C \rightarrow C_{\infty} \quad \text { as } \quad y \rightarrow \infty
$$

Where $\mathrm{k}$ is the thermal conductivity of the fluid.

The mathematical analysis of the problem is simplified by introducing the 
following similarity transformations:

$$
\begin{array}{r}
\eta=y \sqrt{\frac{a}{v}}, \quad \psi=\sqrt{a v} x f(\eta), \\
\theta(\eta)=\frac{T-T_{\infty}}{T_{f}-T_{\infty}}, \quad \phi(\eta)=\frac{C-C_{\infty}}{C_{w}-C_{\infty}}
\end{array}
$$

The equation of continuity is satisfied if we choose a stream function $\psi(x, y)$ such that

$$
u=\frac{\partial \psi}{\partial y}, \quad v=-\frac{\partial \psi}{\partial x}
$$

Using the similarity transformation quantities (6), the governing equations (1)- (4) are transformed into the non-dimensional form as follows:

$$
\begin{aligned}
f^{\prime \prime \prime}+f f^{\prime \prime}-f^{\prime 2}+A^{2}+M\left(A-f^{\prime}\right)+\beta\left(2 f f^{\prime} f^{\prime \prime}-f^{2} f^{\prime \prime \prime}\right) & =0 \\
\theta^{\prime \prime}+\operatorname{Pr}\left[f \theta^{\prime}+N b \phi^{\prime} \theta^{\prime}+N t \theta^{\prime 2}\right] & =0 \\
\phi^{\prime \prime}+\operatorname{PrLef} \phi^{\prime}+\frac{N t}{N b} \theta^{\prime \prime} & =0
\end{aligned}
$$

The corresponding boundary conditions are:

$$
\begin{aligned}
f(0)=0, f^{\prime}(0)=1, \theta^{\prime}(0)=B i(\theta(0)-1), & \phi(0)=1, \quad \text { at } \quad \eta=0, \\
f^{\prime}(\infty) \rightarrow A, \quad \theta(\infty) \rightarrow 0, & \phi(\infty) \rightarrow 0, \text { as } \quad \eta \rightarrow \infty
\end{aligned}
$$

where the governing parameters are defined by

where $f^{\prime}, \theta$ and $\phi$ are the dimensionless velocity, temperature, and concentration respectively. $\eta$ is the similarity variable and the prime denotes differentiation with respect to $\eta$. A(velocity ratio), $\operatorname{Pr}$ (Prandtl number), $\mathrm{Nb}$ (Brownian motion parameter), $\mathrm{Nt}$ (thermophoresis parameter), $\mathrm{Le}$ (Lewis number), $\mathrm{Bi}$ (Biot number), $\beta$ (Deborah number) and $\mathrm{M}$ (magnetic parameter).

If magnetic field, free stream velocity and Deborah number parameters are neglected, the problem is reduced to boundary layer flow of nanofluid past stretching sheet with convective boundary condition which was investigated by Makinde and Olanrewaju (2010).

The important physical quantities of interest in this problem are the skin friction coefficient $C_{f}$, the local Nusselt number $N u_{x}$ and the local Sherwood number $S h_{x}$, respectively, are defined as:

$$
C_{f}=\frac{\tau_{w}}{\rho u_{w}^{2}}, \quad N u_{x}=\frac{x q_{w}}{k\left(T_{w}-T_{\infty}\right)}, S h_{x}=\frac{x h_{m}}{D_{B}\left(\phi_{w}-\phi_{\infty}\right)}
$$

Where the wall shear stress $\tau_{w}$, the wall heat flux $q_{w}$ and wall mass flux $h_{m}$ are given by

$\tau_{w}=\mu(1+\beta) \frac{\partial u}{\partial y}, \quad q_{w}=-k\left(\frac{\partial T}{\partial y}\right)_{y=0}, \quad h_{m}=-D_{B}\left(\frac{\partial \phi}{\partial y}\right)_{y=0}$

By using the above equations, we get

$$
C_{f} \sqrt{R e_{x}}=(1+\beta) f^{\prime \prime}(0), \quad \frac{N u_{x}}{\sqrt{R e_{x}}}=-\theta^{\prime}(0), \quad \frac{S h_{x}}{\sqrt{R e_{x}}}=-\phi^{\prime}(0)
$$

Where $R e_{x}, N u_{x}, S h_{x}$ are local Reynolds number, local Nusselt number and local Sherwood number, respectively.

\section{NUMERICAL SOLUTION}

The flow model for the above coupled ordinary differential equations Eqs. (8)-(10) subjected to the boundary conditions, Eq. (11) for different values of governing parameters viz. Biot number, magnetic parameter $\mathrm{M}$, Prandtl number Pr, velocity ratio parameter A, a Brownian motion parameter $\mathrm{Nb}$, a thermophoresis parameter $\mathrm{Nt}$, a Lewis number Le and $\beta$ (Deborah number) has been numerically solved using Maple 17.0. This software uses a fourth-fifth order Runge-Kutta-Fehlberg method as the default method to solve the boundary value problems numerically. Its accuracy and robustness have been confirmed by different investigators. As a further check on the accuracy of our numerical computations, we have compared our results with the investigators Mahapatra and Gupta (2002) and have found to be in an excellent agreement.

\section{RESULTS AND DISCUSSION}

The transformed momentum, energy and concentration equations (8) (10) subjected to the boundary conditions equations (11) are coupled non-linear differential equation for which closed form solution can't be obtained and hence we required to solve numerically. The governing equations (8) - (10) are solved using Runge-Kutta-Fehlberg method with shooting technique by Maple 17.0 software. We obtained velocity, temperature and concentration profile for different values of governing parameters. The results obtained are displayed through figs. 1-3, figs. 4-10, figs. 11-15 for velocity, temperature and concentration profile respectively. Moreover, fig. 16 and fig. 17 display the graph of skin friction coefficient and local Nusselt number respectively.

Figs. 1 - 3 show the velocity graphs for different values of A, M and $\beta$, respectively, while the other parameters remain fixed.

Fig. 1 illustrates the influence of velocity ratio parameter A on flow velocity. The flow has boundary layer structure and the boundary layer thickness increases as the values of A increase. The velocity graph is (11) feasible when the velocity ratio A is less than or equal to 1.i.e when the velocity of stretching sheet is greater than or equal to the free stream velocity.

Fig. 2 demonstrates the variation of velocity graph with respect to M. As the values of Magnetic parameter $M$ increase, the velocity boundary layer thickness decreases. The magnetic parameter $\mathrm{M}$ represents the importance of magnetic field on the flow field. The presence of transverse magnetic field sets in Lorentz force, which results in retarding force on the velocity field. Therefore, as the values of $\mathrm{M}$ increase, so does the retarding force and hence the velocity decreases.

Fig. 3 reveals the variation of velocity graph with respect to $\beta$ (Deborah number). As the values of $\beta$ increase, the velocity boundary layer thickness increases. This may be due to the fact that as Deborah number increases, the force due to the parameter opposes the flow velocity.

Figs. 4 - 9 represent the variation of temperature with respect to the governing parameters, such as, Biot number parameter Bi, Deborah number $\beta$, Prandtl number Pr, Brownian motion parameter $\mathrm{Nb}$, thermophoresis parameter $\mathrm{Nt}$ and velocity ratio parameter $\mathrm{A}$.

Fig. 4 shows the effect of Biot number(Bi) on temperature field. It is found that both the sheet surface and the nanofluid temperature increase when $\mathrm{Bi}$ is increased. This leads to an increase in thermal boundary layer thickness. As the value of parameter Bi increases, the intensity of convective heating on the sheet surface increases, which leads to an increasing rate of convective heat transfer from the hot fluid on the lower surface of the sheet to the nanofluid on the upper surface. The graph also reveals that $\theta(\eta)$ increases rapidly near the surface due to the increasing values of $\mathrm{Bi}$.

Fig. 5 displays the influence of Deborah number $\beta$ on temperature profile. As the values of $\beta$ increase, the thermal boundary layer thickness increases. This may be due to the fact that as the as the values of $\beta$ increase thermal difussivity decreases, which induces the rise of temperature in the boundary layer.

Fig. 6 represents variation of temperature with respect to Brownian motion parameter $\mathrm{Nb}$. As the values of $\mathrm{Nb}$ increase, the temperature graph is decreasing. The graph also reveals that the thermal boundary layer thickness increases when the values of $\mathrm{Nb}$ increase. Moreover, the surface temperature increases as the values of $\mathrm{Nb}$ increase.

Fig. 7 shows the influence of the change of thermophoresis parameter $\mathrm{Nt}$ on temperature graph. It can be noticed that as thermophoesis parameter increases, the thermal boundary layer thickness increases and the temperature gradient at the surface decreases (in absolute value) as $\mathrm{Nt}$ 
increases. Therefore, the local Nusselt number $-\theta^{\prime}(0)$, which represents the heat transfer rate at the surface decreases. Consequently, temperature on the surface of a sheet increases. This is due to the fact that the thermophoresis Parameter Nt is directly proportional to the heat transfer coefficient associated to the fluid. The thermal resistance on the hot fluid side is inversely proportional to $h_{f}$. Thus, as Nt increases, the hot fluid side convection resistance decreases, as a result, the surface temperature $\theta(0)$ increases.

Fig. 8 represents the variation of temperature graph with respect to Prandtl number Pr. The graph depicts that the temperature and thermal boundary thickness decrease when the values of Prandtl number Pr increase at a fixed value of $\eta$. This is due to the fact that a higher Prandtl number fluid has relatively low thermal conductivity, which reduces conduction and there by the thermal boundary layer thickness, and as a result, temperature decreases. Increasing Pr is to increase the heat transfer rate at the surface because the temperature gradient at the surface increases. The influence of Prandtl on Newtonian fluids is similar to what we have observed in nanofluid. Therefore, these properties are also inherited by nanofluids.

Fig. 9 shows the variation of temperature profile in response to a change in the values of velocity ratio parameter A. It is observed that as the velocity ratio parameter A increases, the thermal boundary layer thickness decreases. Moreover, the temperature at the surface decreases (in absolute value) as A increases. As a result, local Nusselt number $\theta^{\prime}(0)$ on the surface of a sheet increases. This is due to the fact that the velocity ratio Parameter B is directly proportional to the heat transfer coefficient associated with hot fluid $h_{f}$. The thermal resistance on the hot fluid side is inversely proportional to $h_{f}$. Thus, as A increases, the hot fluid side convection resistance decreases; as a result, the surface temperature $\theta(0)$ decreases. The graph also shows that $\theta(0) \rightarrow 1$ as $B i \rightarrow \infty$.

Figs. $10-14$ demonstrate the variation of nanoparticle concentration with respect to the change of governing parameters, viz.Lewis number $\mathrm{Le}$, Biot number $\mathrm{Bi}$, Brownian motion parameter $\mathrm{Nb}$ and thermophoresis parameter Nt.

As it is noticed from graph 10, as Lewis number increases, the concentration graph decreases. Moreover, the concentration boundary layer thickness decreases as Lewis number increases. This is probably due to the fact that mass transfer rate increases as Lewis number increases. It also reveals that the concentration gradient at surface of the sheet increases.

Fig. 11 shows the variation of concentration graph with respect to a change in Biot number Bi. From the graph, it is possible to see that as the values of Biot number parameter $\mathrm{Bi}$ increase, the concentration graph is decreasing. Moreover, the graph reveals that as the values of Bi increase, the concentration boundary layer thickness is increasing.

Fig. 12 shows the influences of thermophoresis parameter on temperature profile. As the values of thermophoresis parameter Nt increases, the concentration boundary layer thickness increases. This indicates that an increment in thermophosis parameter induces resistance to the diffusion of mass. This results in the reduction of concentration gradient on the surface.

Fig. 13 elucidates the variation of concentration graph with respect to Brownian motion parameter $\mathrm{Nb}$. As the values of Brownian motion parameter $\mathrm{Nb}$ increase, the concentration boundary layer thickness decreases.

Fig. 14displays the variation of concentration graph with respect to magnetic parameter $M$. As the values of $M$ increase, the concentration boundary layer thickness increases which is opposite to the scenario observed in fig14.

Figs. 15-16 shows the variation of the skin friction coefficient $f^{\prime \prime}(0)$ with respect to $\mathrm{A}$ and $\beta$ as the values of magnetics parameter $\mathrm{M}$ increase. As the values of $\mathrm{M}$ increase, the graph of skin friction coefficient increases, however, as the values $\beta$ increases the graph decreases and the boundary thickness decreases.
Table 1 Comparison of skin friction coefficient $f^{\prime \prime}(0)$ for different values of velocity ratio parameter $\mathrm{A}$ when $\mathrm{M}=0, \beta=0, \mathrm{Bi}=1000$.

\begin{tabular}{lccc}
\hline $\mathrm{A}$ & $\alpha$ & $\delta$ & Present result \\
\hline 0.1 & -0.9694 & -0.9694 & -0.9694 \\
0.2 & -0.9181 & -0.9181 & -0.9181 \\
0.5 & -0.6673 & -0.6673 & -0.6673 \\
2.0 & 2.0175 & 2.0175 & 2.0175 \\
3.0 & 4.7293 & 4.7293 & 4.7293 \\
5.0 & - & - & 11.7520 \\
10.0 & - & - & 36.2574
\end{tabular}

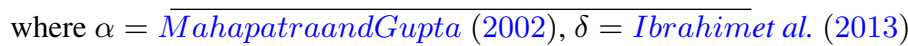

Table 2 Comparison of local Nusselt number $-\theta^{\prime}(0)$ at $\beta=A=M=$ $0.0, N t=N b=10^{-10}, L e=2$ for different values of Pr with perviously published result

\begin{tabular}{lccc}
\hline $\operatorname{Pr}$ & $\mathrm{a}$ & $\mathrm{b}$ & Present result \\
\hline 0.07 & 0.0663 & 0.0656 & 0.0656 \\
0.2 & 0.1691 & 0.1691 & 0.1691 \\
0.7 & 0.4539 & 0.4539 & 0.4539 \\
2.0 & 0.9113 & 0.9113 & 0.9113 \\
7.0 & 1.8954 & 1.8954 & 1.8954 \\
20.0 & 3.3539 & 3.3539 & 3.3539 \\
70.0 & 6.4621 & 6.4621 & 6.4621 \\
\hline Where $a=$ KhanandGorla $(2012)$ and \\
$b=$ MakindeandOlanrewaju $(2010)$
\end{tabular}

Fig. 16 shows the variation of the skin friction coefficient $-f^{\prime \prime}(0)$ with respect to $\mathrm{A}$ as the values of magnetics parameter $\mathrm{M}$ increase. As the values of $\mathrm{M}$ increase, the graph increases and the boundary thickness also increases.

Fig. 17 displays the effect of Brownian motion parameter on local Nusselt number against thermophoresis parameter $\mathrm{Bi}$. As the values of Bi parameter increase, the graph of local Nusselt number $-\theta^{\prime}(0)$ increases and the thermal boundary layer thickness also increases.

Table 1 shows the comparison of the variation of skin friction coefficient $f^{\prime \prime}(0)$ for different values of velocity ratio parameter A with previous studies. From the table it is possible to see that our result is in an excellent agreement with the results given by researchers Mahapatra and Gupta (2002) and Ibrahim et al. (2013) in limiting conditions. Moreover, to check the accuracy of the numerical solutions, a comparison of heat transfer rate for different values of Pr is made with Makinde and Olanrewaju (2010) and Khan and Gorla (2012) and we have found an excellent agreement with them.

From table 1 and 2, we can see that the present result is in an excellent agreement with the results reported by previous studies under limiting conditions. Therefore, we are confident that our numerical method is suitable for the analysis of the problem.

The variation of $f^{\prime \prime}(0),-\theta^{\prime}(0)$ and $-\phi^{\prime}(0)$ with respect to velocity ratio $\mathrm{A}, \mathrm{M}, \mathrm{Bi}$ and $\beta$ is given in table 3 . From the table, it is possible to see that skin friction coefficient increases when velocity ratio parameter $\mathrm{A}$ and Deborah number $\beta$ increase; however, it remain constant as the values of convective parameter $\mathrm{Bi}$ increase. Moreover, the table illustrates that the local Nusselt number $-\theta^{\prime}(0)$ of the flow field increases as the values of $\mathrm{A}, \mathrm{Bi}$ and $\beta$ increase. It is also indicated that the local Sherwood number $\phi^{\prime}(0)$ increases as the values of the three parameters $\mathrm{A}, \mathrm{Bi}$ and $\beta$ increase. All the three quantities of interest skin friction coefficient, local Nusselt number and local Sherwood number decrease as the values of $\mathrm{M}$ increase. 
Table 3 Computed values of skin friction coefficient $f^{\prime \prime}(0)$, local Nusselt number $-\theta^{\prime}(0)$ and local Sherwood number $-\phi^{\prime}(0)$ for different values of $A, M$, Bi $\beta$ and when $N b=N t=0.5, \operatorname{Pr}=2$, $L e=5$

\begin{tabular}{ccccccc}
\hline $\mathrm{A}$ & $\mathrm{M}$ & $\mathrm{Bi}$ & $\beta$ & $f^{\prime \prime}(0)$ & $-\theta^{\prime}(0)$ & $-\phi^{\prime}(0)$ \\
\hline 0.0 & 1 & 0.5 & 0.01 & -1.4160 & 0.1943 & 1.4336 \\
0.2 & & & & -1.3815 & 0.1970 & 1.4536 \\
0.6 & & & & -1.1228 & 0.2107 & 1.5599 \\
1.0 & 1 & & & -0.6565 & 0.2254 & 1.6870 \\
& 2 & & & -1.1179 & 0.2144 & 1.5874 \\
& 3 & & & -1.4739 & 0.2054 & 1.5088 \\
& 4 & & & -1.7695 & 0.1977 & 1.4438 \\
& 2 & 0.1 & & -1.1179 & 0.0814 & 1.5780 \\
& & 0.5 & & -1.1179 & 0.2144 & 1.5874 \\
& & 1 & & -1.1179 & 0.2601 & 1.5980 \\
& & 10 & & -1.1179 & 0.3120 & 1.6170 \\
& & 20 & & -1.1179 & 0.3152 & 1.6481 \\
& & 0.5 & 0.01 & -1.1179 & 0.2144 & 1.5874 \\
& & 0.0 & -1.1165 & 0.2145 & 1.5878 \\
& & & -1.0 & -0.9828 & 0.2185 & 1.6234 \\
& & & -2.0 & -0.8664 & 0.2220 & 1.6550 \\
\hline
\end{tabular}

\section{CONCLUSIONS}

A numerical study is presented for a boundary layer and MHD stagnation point flow of upper-convected Maxwell fluid flow over a stretching sheet with convective boundary conditions. Using similarity variables, the governing equations are transformed into a set of differential equations, where numerical solution has been given for different governing parameters. The results indicate that the velocity field is sensitive when the Deborah number $\beta$ is negative. Moreover, the velocity graph has shown a change when the velocity ratio is less than or equal to 1 . The velocity boundary layer thickness increases as the values of Deborah number $\beta$ increase. The inclusion of the effect of Deborah number in the presence of nanoparticle makes this study a novel one. The following conclusions are drawn from the analysis:

- The thickness of velocity boundary layer increases with an increase in A.

- The thickness of the velocity boundary layer increases as the values of Deborah number $\beta$ increase.

- The thickness of thermal boundary layer increases with an increase in Biot number and Brownian motion parameters.

- The thickness of thermal boundary layer decreases as Deborah number $\beta$, Prandtl number parameter Pr and velocity ratio A increase.

- The thickness of concentration boundary layer increases with an increase in the values of $\mathrm{Nt}$ and $\mathrm{Bi}$ parameters.

- The thickness of concentration boundary layer decreases with an increase in Lewis number Le.

\section{ACKNOWLEDGEMENTS}

The author wishes to express his very sincere thanks to referees for their valuable comments and suggestions.

\section{NOMENCLATURE}

A Velocity ratio

$B i \quad$ Biot number

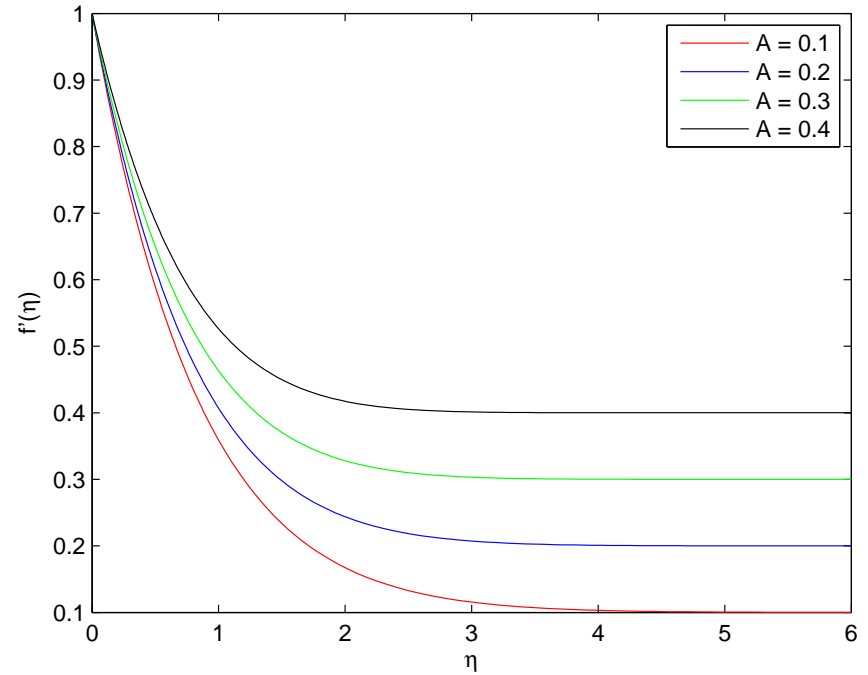

Fig. 1 Velocity graph for different values of A when $\beta=0.1, M=0.2$

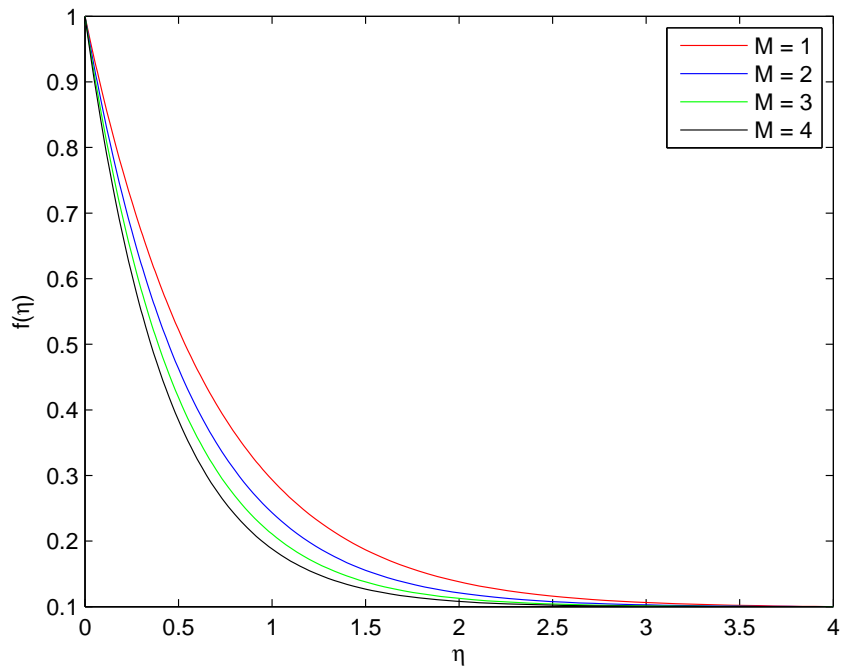

Fig. 2 Velocity graph for different values of $\mathrm{M}$ when $\beta=0.1, A=0.1$

$B_{0} \quad$ Strength of Magnetic field

$C_{f} \quad$ Skin friction coefficient

$C_{\infty} \quad$ Ambient concentration

$D_{B} \quad$ Brownian diffusion coefficient

$D_{T} \quad$ Thermophoresis diffusion coefficient

f Dimensionless velocity stream function

$h_{f} \quad$ Heat transfer coefficient

$\mathrm{k} \quad$ Thermal conductivity

Le Lewis number

M Magnetic parameter

$\mathrm{Nb} \quad$ Brownian motion parameter

$\mathrm{Nt}$ Thermophoresis parameter

$N u_{x} \quad$ Local Nusselt number

Pr Prandtl number

$R e_{x} \quad$ Local Reynolds number

$S h_{x} \quad$ Local Sherwood number

$\mathrm{T} \quad$ Temperature of the fluid inside

the boundary layer

$T_{w} \quad$ Uniform temperature over the surface of the plate

$T_{f} \quad$ Temperature of a hot fluid

$T_{\infty} \quad$ Ambient temperature 


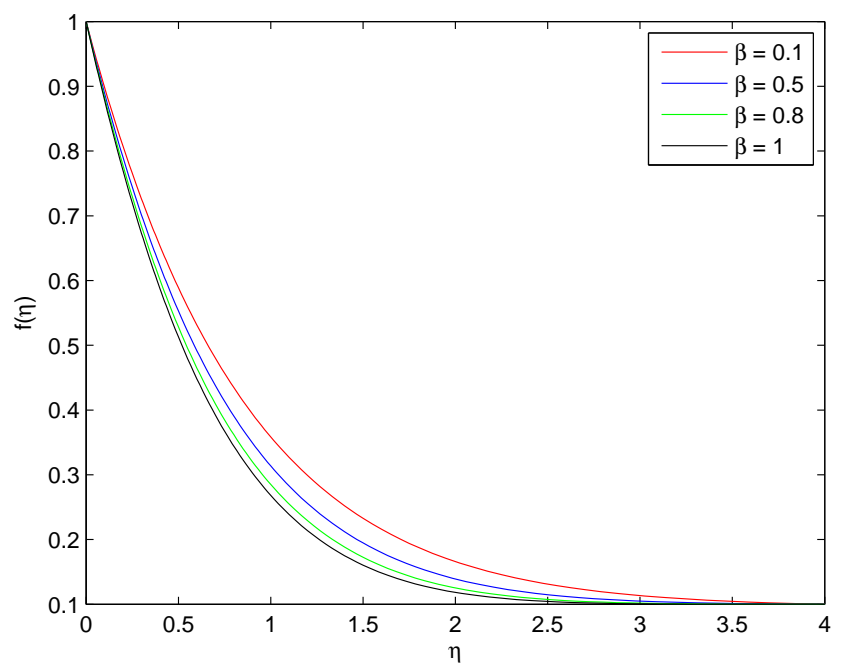

Fig. 3 Velocity graph for different values of $\beta$ when $M=0.2, A=0.1$

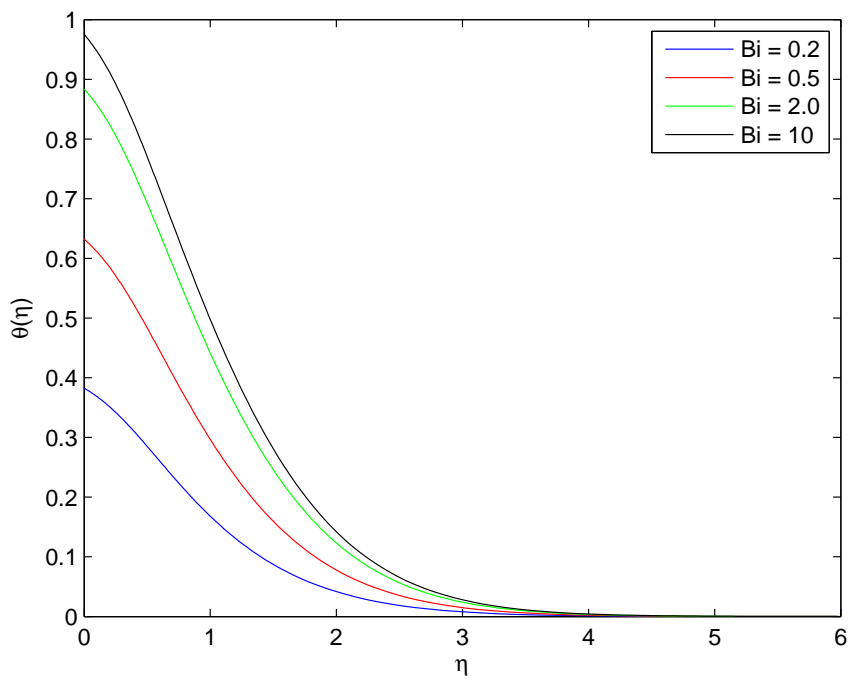

Fig. 4 Temperature graph for different values of Bi when $N b=N t=$ $0.5, L e=5, P r=2, \beta=1, M=0.2, A=0.1$

$u, v$

Velocity component

along $x$ - and $y$-direction

Greeks

$\alpha \quad$ Thermal diffusivity

$\beta \quad$ Deborah number

$\eta \quad$ Dimensionless similarity variable

$\mu \quad$ Dynamic viscosity of the fluid

$v \quad$ Kinematic viscosity of the fluid

$(\rho)_{f} \quad$ Density of the fluid

$(\rho c)_{f} \quad$ Heat capacity of the fluid

$(\rho c)_{p} \quad$ Effective heat capacity of a nanoparticle

$\psi \quad$ Stream function

$\sigma \quad$ Electrical conductivity

$\phi_{w} \quad$ Dimensionless concentration

function at the surface

$\phi_{\infty} \quad$ Dimensionless concentration

function at large values of $y$

$\theta \quad$ Dimensionless temperature

$\tau \quad$ Parameter defined by $\frac{(\rho c)_{p}}{(\rho c)_{f}}$

Subscripts

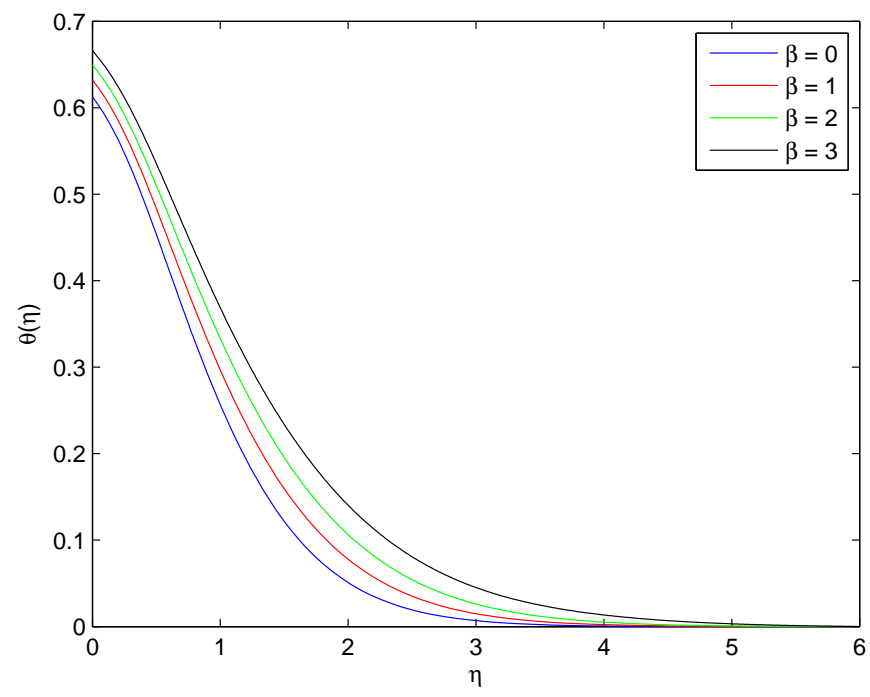

Fig. 5 Temperature graph for different values of $\beta$ when $N b=N t=$ $B i=0.5, L e=5, \operatorname{Pr}=2, M=0.2, A=0.1$

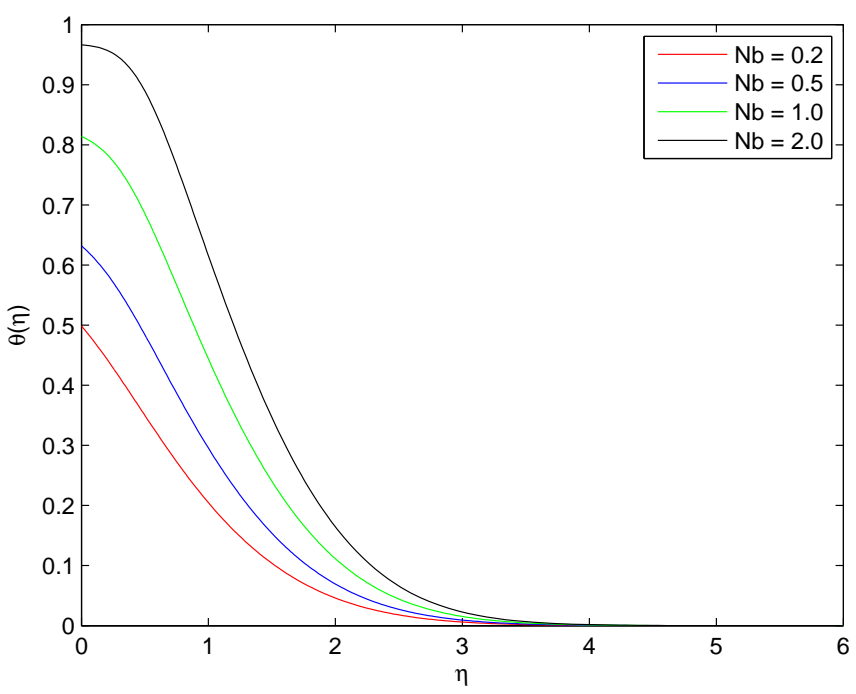

Fig. 6 Temperature graph for different values of $\mathrm{Nb}$ when $N t=B i=$ $0.5, L e=5, \operatorname{Pr}=2, \beta=2, M=0.2, A=0.2$

$\infty \quad$ Condition at the free stream

w Condition at the surface

\section{REFERENCES}

Abel, M.S., Sanjayanand, E., and Nandeppanavar, M.M., 2008, "Viscoelastic MHD Flow and Heat Transfer over a Stretching Sheet with Viscous and Ohmic Dissipations," Communications in Nonlinear Science and Numerical Simulation, 13(9), 1808-1821. http://dx.doi.org/10.1016/j.cnsns.2007.04.007.

Abel, M.S., Tawade, J.V., and Nandeppanavar, M.M., 2012, "MHD Flow and Heat Transfer for the Upper-Convected Maxwell Fluid over a Stretching Sheet," Meccanica, 47(2), 385-393.

http://dx.doi.org/10.1007/s11012-011-9448-7.

Aliakbar, V., Alizadeh-Pahlavan, A., and Sadeghy, K., 2009, "Influence of Thermal Radiation on MHD Flow of Maxwellian Fluids above Stretching Sheets," Communications in Nonlinear Science and Numerical Simu- 


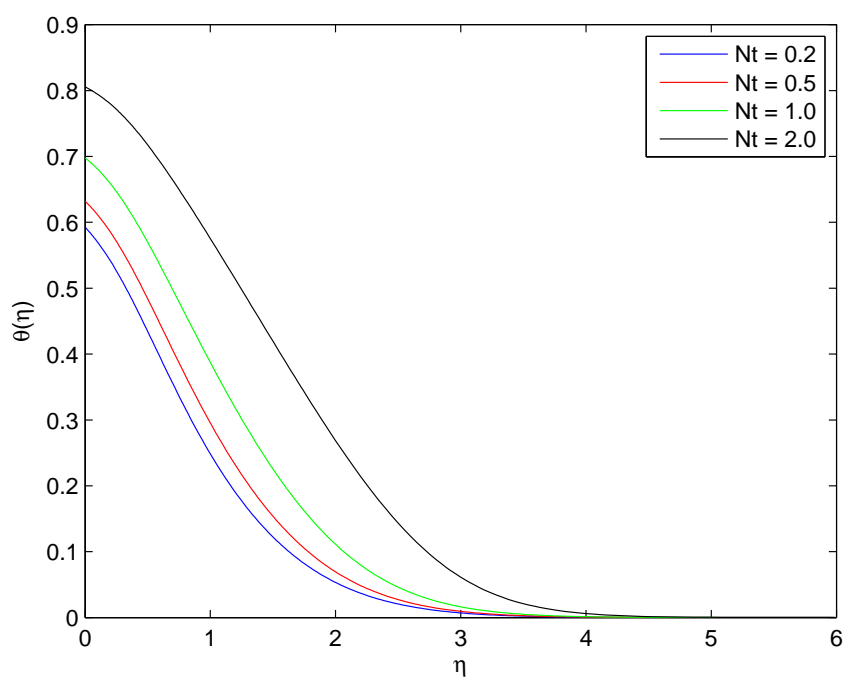

Fig. 7 Temperature graph for different values of $\mathrm{Nt}$ when $\mathrm{Nb}=\mathrm{Bi}=$ $0.5, L e=5, \operatorname{Pr}=2, \beta=2, M=0.3, A=0.2$

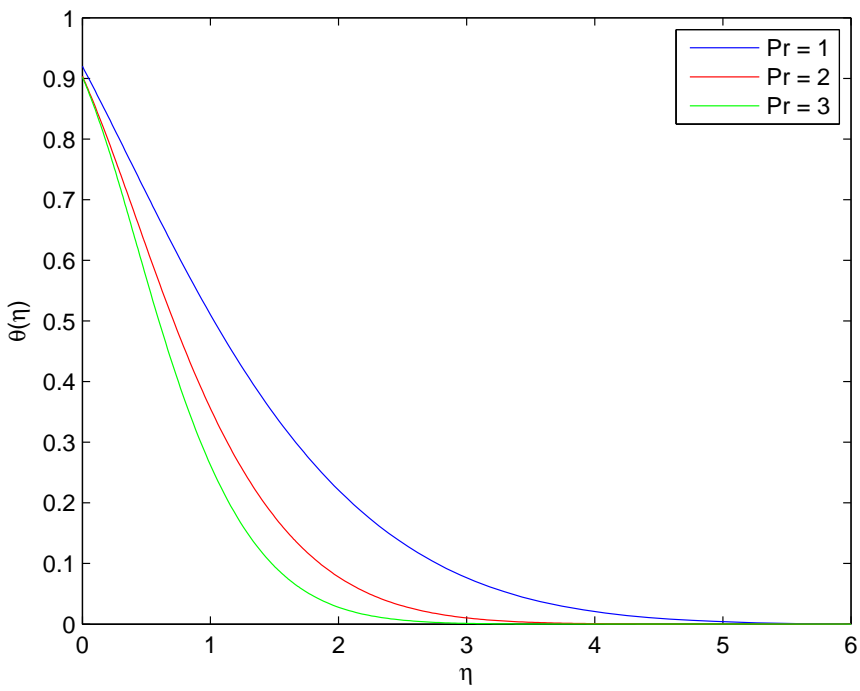

Fig. 8 Temperature graph for different values of $\operatorname{Pr}$ when $N b=N t=$ $M=0.2, L e=5, A=0.2, B i=5, \beta=2$

lation, 14(3), 779-794.

http://dx.doi.org/10.1016/j.cnsns.2007.12.003.

Alizadeh-Pahlavan, A., Aliakbar, V., Vakili-Farahani, F., and Sadeghy, K., 2009, "MHD Flows of UCM Fluids above Porous Stretching Sheets using Two-Auxiliary-Parameter Homotopy Analysis Method," Communications in Nonlinear Science and Numerical Simulation, 14(2), 473488.

http://dx.doi.org/10.1016/j.cnsns.2007.09.011.

Aziz, A., 2009, "Similarity Solution for Laminar Thermal Boundary Layer over a Flat Plate with a Convective Surface Boundary Condition," Communications in Nonlinear Science and Numerical Simulation, 14(4), 1064-1068.

http://dx.doi.org/10.1016/j.cnsns.2008.05.003.

Aziz, A., 2010, "Hydrodynamic and Thermal Slip Flow Boundary Layers over a Flat Plate with Constant Heat Flux Boundary Condition," Сотmunications in Nonlinear Science and Numerical Simulation, 15(3), 573580.

http://dx.doi.org/10.1016/j.cnsns.2009.04.026.

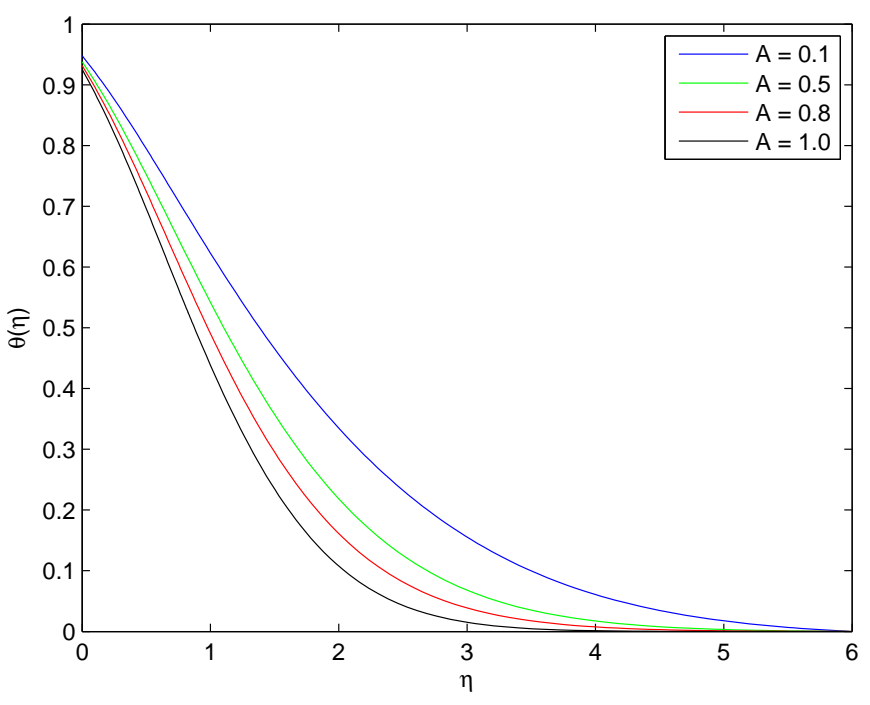

Fig. 9 Temperature graph for different values of velocity ratio parameter A when $N b=N t=M=0.2, L e=5, B i=5, P r=2$, $\beta=2$

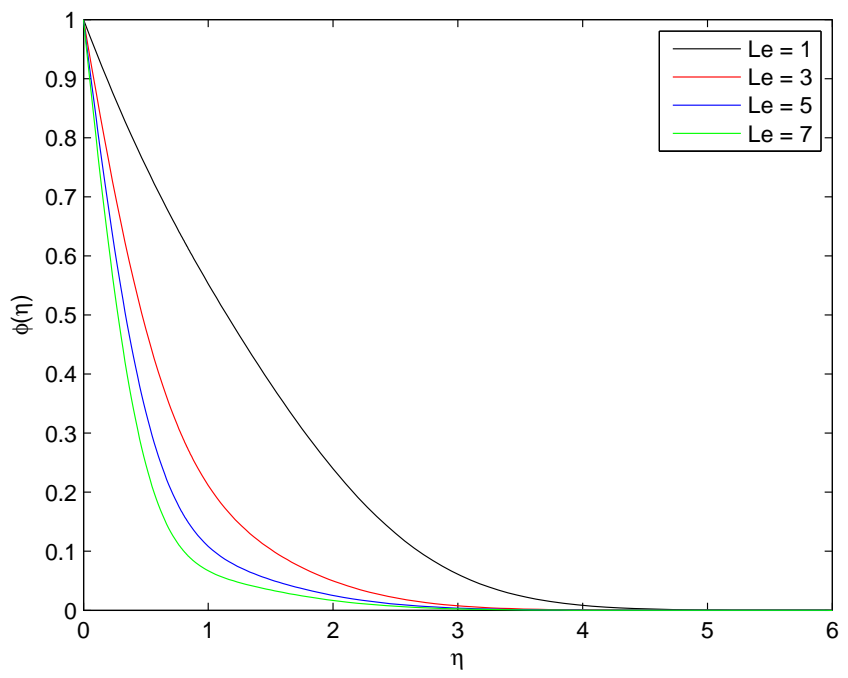

Fig. 10 Concentration graph for different values of Le when when $\mathrm{Nb}=$ $N t=0.5, B i=5, M=0.2, A=1, \operatorname{Pr}=1, \beta=2$

Bachok, N., Ishak, A., Nazar, R., and Pop, I., 2010, "Flow and Heat Transfer at a General Three-Dimensional Stagnation Point in a Nanofluid," Physica B: Condensed Matter, 405(24), 4914-4918. http://dx.doi.org/10.1016/j.physb.2010.09.031.

Bataller, R.C., 2008, "Radiation Effects for the Blasius and Sakiadis Flows with a Convective Surface Boundary Condition," Applied Mathematics and Computation, 206(2), 832-840. http://dx.doi.org/10.1016/j.amc.2008.10.001.

Hady, F., Ibrahim, F., Abdel-Gaied, S., and Eid, M.R., 2011, "BoundaryLayer Non-Newtonian Flow over Vertical Plate in Porous Medium Saturated with Nanofluid," Applied Mathematics and Mechanics, 32(12), 1577-1586.

http://dx.doi.org/10.1007/s10483-011-1524-7.

Hayat, T., Abbas, Z., and Ali, N., 2008, "MHD Flow and Mass Transfer of a Upper-Convected Maxwell Fluid Past a Porous Shrinking Sheet with Chemical Reaction Species," Physics Letters A, 372(26), 4698-4704. http://dx.doi.org/10.1016/j.physleta.2008.05.006. 


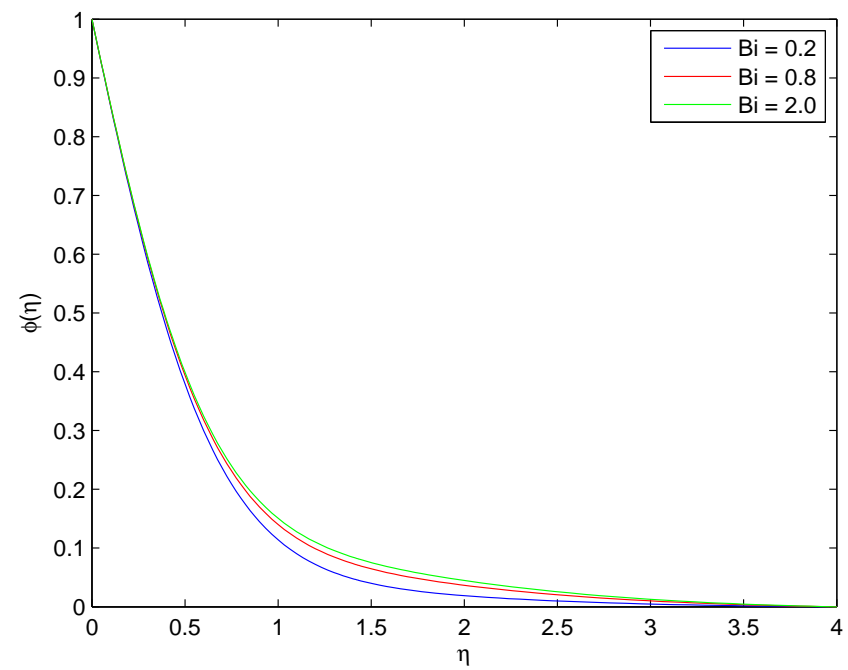

Fig. 11 Concentration graph for different values of $\mathrm{Bi}$ when $\mathrm{Nb}=N t=$ $0.5, M=0.2, L e=5, A=0.4, \operatorname{Pr}=1, \beta=2$

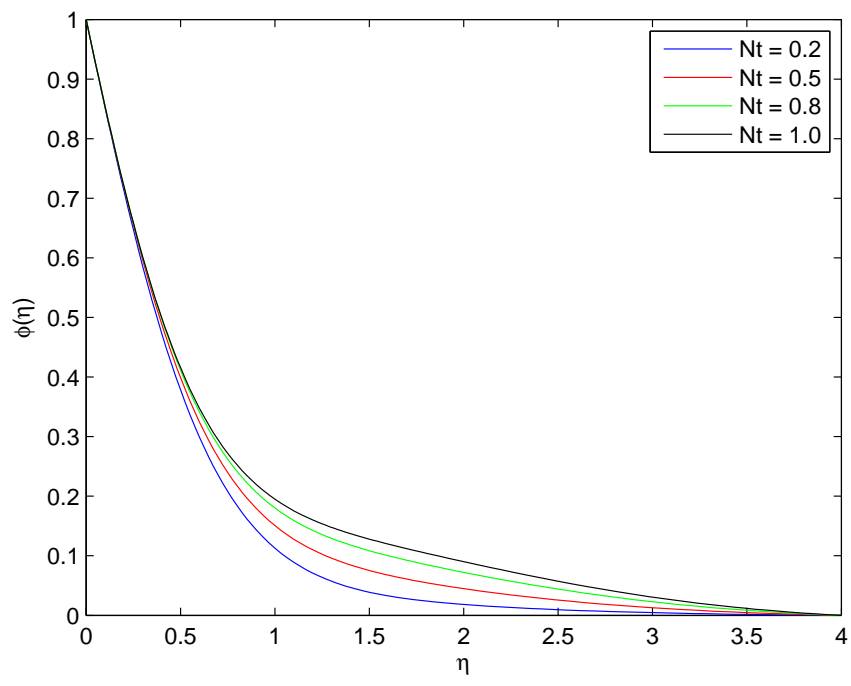

Fig. 12 Concentration graph for different values of $\mathrm{Nt}$ when $\mathrm{Nb}=\mathrm{Bi}=$ $0.5, M=0.2, A=0.4, L e=5, \operatorname{Pr}=1, \beta=2$

Hayat, T., Abbas, Z., and Sajid, M., 2009, "MHD Stagnation-Point Flow of an Upper-Convected Maxwell Fluid over a Stretching Surface," Chaos, Solitons \& Fractals, 39(2), 840-848.

http://dx.doi.org/10.1016/j.chaos.2007.01.067.

Hayat, T., Awais, M., Qasim, M., and Hendi, A.A., 2011, "Effects of Mass Transfer on the Stagnation Point Flow of an Upper-Convected Maxwell (UCM) Fluid," International Journal of Heat and Mass Transfer, 54(15), 3777-3782.

http://dx.doi.org/10.1016/j.ijheatmasstransfer.2011.03.003.

Hayat, T., Mustafa, M., Shehzad, S., and Obaidat, S., 2012a, "Melting Heat Transfer in the Stagnation-Point Flow of an Upper-Convected Maxwell (UCM) Fluid Past a Stretching Sheet," International Journal for Numerical Methods in Fluids, 68(2), 233-243.

http://dx.doi.org/10.1002/fld.2503.

Hayat, T., and Qasim, M., 2010, "Influence of Thermal Radiation and Joule Heating on MHD Flow of a Maxwell Fluid in the Presence of Thermophoresis," International Journal of Heat and Mass Transfer, 53(21),

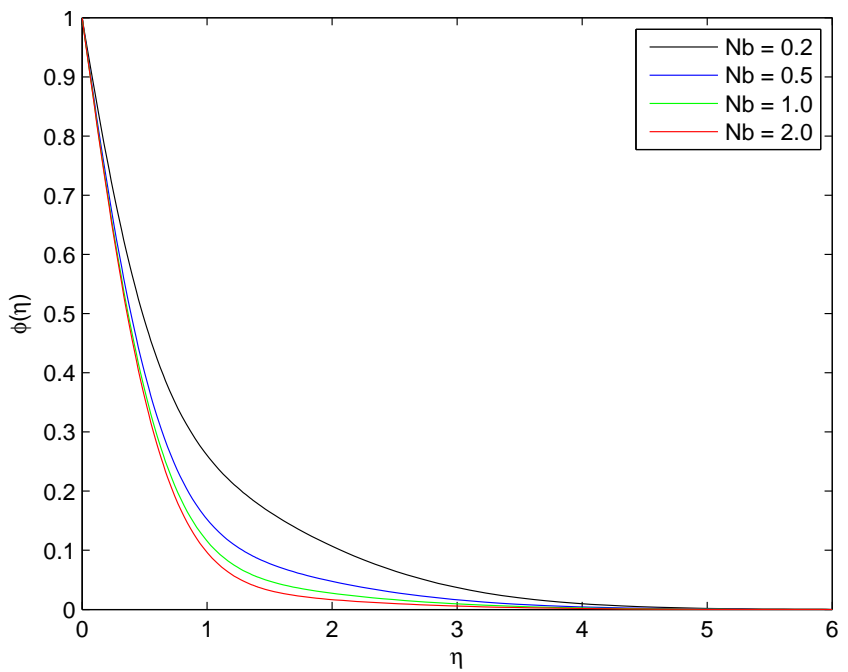

Fig. 13 Concentration graph for different values of $\mathrm{Nb}$ when $N t=B i=$ $0.5, M=0.2, A=0.4, L e=5, \operatorname{Pr}=1, \beta=2$

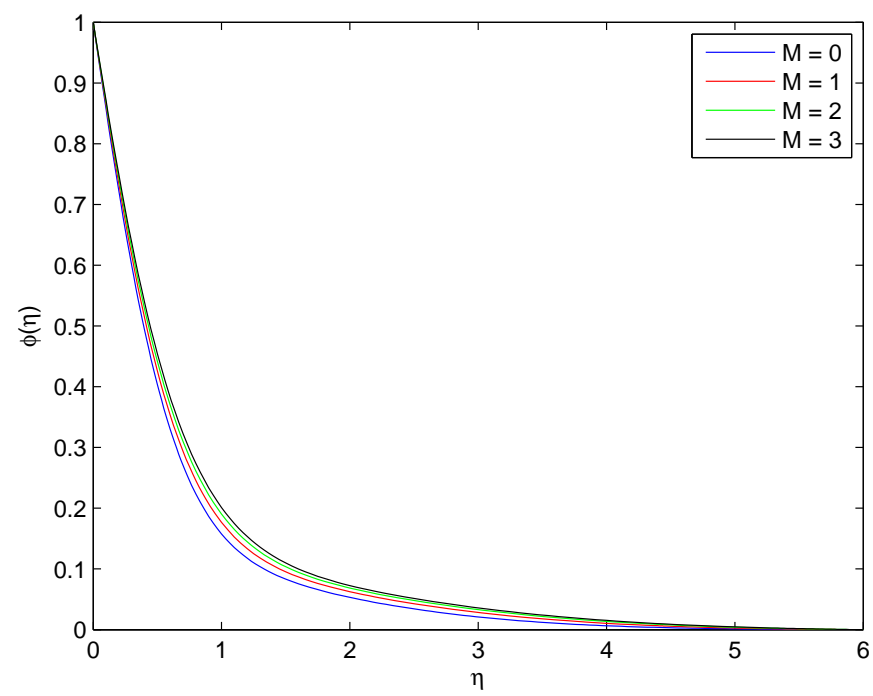

Fig. 14 Concentration graph for different values of $\mathrm{M}$ when $\mathrm{Nb}=\mathrm{Nt}=$ $0.5, B i=2, A=0.1, L e=5, \operatorname{Pr}=1, \beta=1$

$4780-4788$.

http://dx.doi.org/10.1016/j.ijheatmasstransfer.2010.06.014.

Hayat, T., Safdar, A., Awais, M., and Mesloub, S., 2012b, "Soret and Dufour Effects for Three-Dimensional Flow in a Viscoelastic Fluid over a Stretching Surface," International Journal of Heat and Mass Transfer, 55(7), 2129-2136.

http://dx.doi.org/10.1016/j.ijheatmasstransfer.2011.12.016.

Hsiao, K.L., 2011, "MHD Stagnation Point Viscoelastic Fluid Flow and Heat Transfer on a Thermal Forming Stretching Sheet with Viscous Dissipation," The Canadian Journal of Chemical Engineering, 89(5), 12281235.

http://dx.doi.org/10.1002/cjce.20474.

Ibrahim, W., and Makinde, O., 2013, "Effect of Double Stratification on Boundary-Layer Flow and Heat Transfer of Nanofluid over a Vertical Plate," Computers \& Fluids, 86, 433-441.

http://dx.doi.org/10.1016/j.compfluid.2013.07.029. 


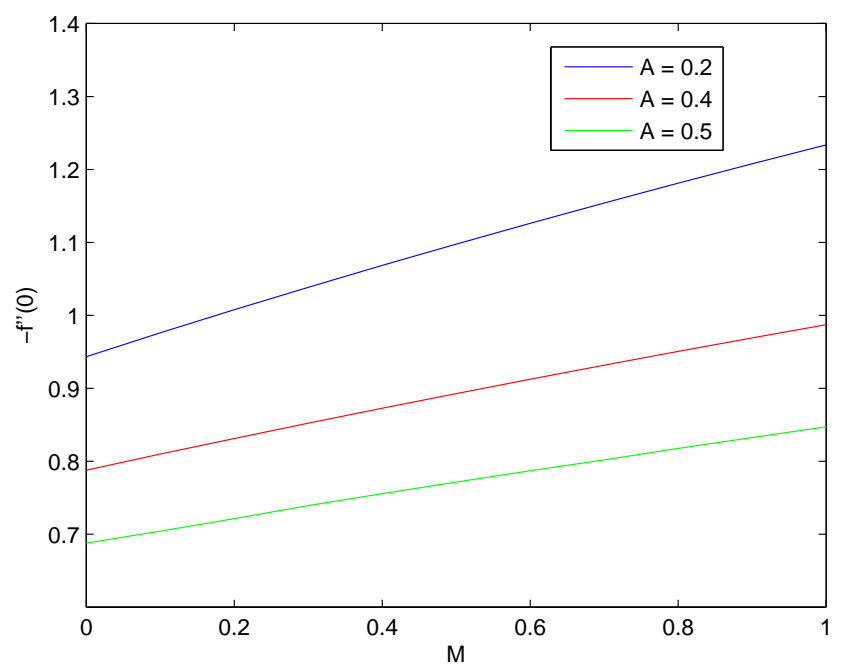

Fig. 15 Graph of skin friction coefficient $-f^{\prime \prime}(0)$ for different values of $\mathrm{M}$ along with velocity ratio parameter $\mathrm{A}$ when $\mathrm{Nb}=\mathrm{Nt}=$ $0.5, B i=2, \operatorname{Pr}=1, \beta=0.1, L e=5$

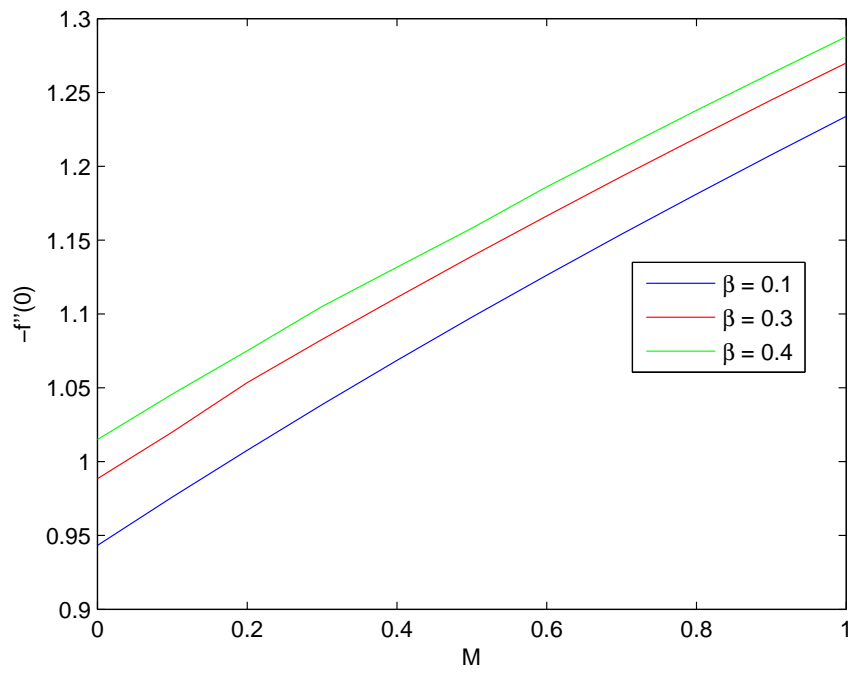

Fig. 16 Graph of skin friction coefficient $-f^{\prime \prime}(0)$ for different values of $\mathrm{M}$ along with $\beta$ when $N b=N t=0.5, B i=2, \operatorname{Pr}=1, A=0.1$, $L e=5$

Ibrahim, W., and Shankar, B., 2013, "MHD Boundary Layer Flow and Heat Transfer of a Nanofluid Past a Permeable Stretching Sheet with Velocity, Thermal and Solutal Slip Boundary Conditions," Computers \& Fluids, 75, 1-10. http://dx.doi.org/10.1016/j.compfluid.2013.01.014.

Ibrahim, W., Shankar, B., and Nandeppanavar, M.M., 2013, "MHD Stagnation Point Flow and Heat Transfer due to Nanofluid towards a Stretching Sheet," International Journal of Heat and Mass Transfer, 56(1), 1-9. http://dx.doi.org/10.1016/j.ijheatmasstransfer.2012.08.034.

Ibrahim, W., and Shanker, B., 2012, "Boundary-Layer Flow and Heat Transfer of Nanofluid over a Vertical Plate with Convective Surface Boundary Condition," Journal of Fluids Engineering, 134(8), 081203. http://dx.doi.org/10.1115/1.4007075.

Ishak, A., 2010, "Similarity Solutions for Flow and Heat Transfer over a Permeable Surface with Convective Boundary Condition," Applied Mathematics and Computation, 217(2), 837-842.

http://dx.doi.org/10.1016/j.amc.2010.06.026.

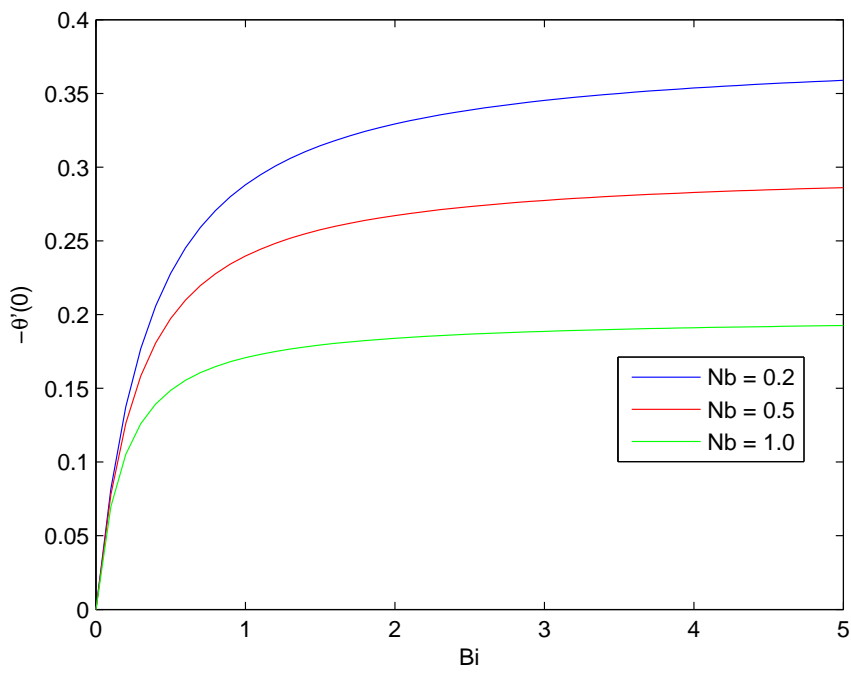

Fig. 17 Graph of local Nusselt number $-\theta^{\prime}(0)$ for different values of $\mathrm{Nb}$ when $N t=0.5, L e=5, \beta=2, A=M=0.2, \operatorname{Pr}=2$

Ishak, A., Yacob, N.A., and Bachok, N., 2011, "Radiation Effects on the Thermal Boundary Layer Flow over a Moving Plate with Convective Boundary Condition," Meccanica, 46(4), 795-801. http://dx.doi.org/10.1007/s11012-010-9338-4.

Khan, W.A., and Gorla, R.S.R., 2012, "Heat and Mass Transfer in PowerLaw Nanofluids Over a Nonisothermal Stretching Wall with Convective Boundary Condition," Journal of Heat Transfer, 134(11), 112001. http://dx.doi.org/10.1115/1.4007138.

Kumari, M., and Nath, G., 2009, "Steady Mixed Convection StagnationPoint Flow of Upper-Convected Maxwell Fluids with Magnetic Field," International Journal of Non-Linear Mechanics, 44(10), 1048-1055. http://dx.doi.org/10.1016/j.ijnonlinmec.2009.08.002.

Kumari, M., Pop, I., and Nath, G., 2010, "Transient MHD Stagnation Flow of a Non-Newtonian Fluid due to Impulsive Motion from Rest," International Journal of Non-Linear Mechanics, 45(5), 463-473. http://dx.doi.org/10.1016/j.ijnonlinmec.2010.01.002.

Mahapatra, T.R., and Gupta, A., 2002, "Heat Transfer in Stagnation-Point Flow towards a Stretching Sheet," Heat and mass transfer, 38(6), 517521.

http://dx.doi.org/10.1007/s002310100215.

Mahapatra, T.R., Nandy, S., and Gupta, A., 2009, "Magnetohydrodynamic Stagnation-Point Flow of a Power-Law Fluid towards a Stretching Surface," International Journal of Non-Linear Mechanics, 44(2), 124129.

http://dx.doi.org/10.1016/j.ijnonlinmec.2008.09.005.

Makinde, O., and Olanrewaju, P., 2010, "Buoyancy Effects on Thermal Boundary Layer over a Vertical Plate with a Convective Surface Boundary Condition," Journal of Fluids Engineering, 132(4), 044502. http://dx.doi.org/10.1115/1.4001386.

Merkin, J., and Pop, I., 2011, "Forced Convection Flow of a Uniform Stream over a Flat Surface with a Convective Surface Boundary Condition," Communications in Nonlinear Science and Numerical Simulation, 16(9), 3602-3609.

http://dx.doi.org/10.1016/j.cnsns.2011.01.007.

Motsa, S., Hayat, T., and Aldossary, O., 2012, "MHD Flow of UpperConvected Maxwell Fluid over Porous Stretching Sheet using Successive 
Taylor Series Linearization Method," Applied Mathematics and Mechanics, 33(8), 975-990.

http://dx.doi.org/10.1007/s10483-012-1599-x.

Mustafa, M., Hayat, T., Pop, I., Asghar, S., and Obaidat, S., 2011, "Stagnation-Point Flow of a Nanofluid towards a Stretching Sheet," International Journal of Heat and Mass Transfer, 54(25), 5588-5594.

http://dx.doi.org/10.1016/j.ijheatmasstransfer.2011.07.021.

Rajagopal, K., 2012, "a Note on Novel Generalizations of the Maxwell Fluid Model," International Journal of Non-Linear Mechanics, 47(1), 72-76.

http://dx.doi.org/10.1016/j.ijnonlinmec.2011.08.015.

Renardy, M., and Wang, X., 2012, "Boundary Layers for the Upper Convected Maxwell Fluid,” Journal of Non-Newtonian Fluid Mechanics, 189, $14-18$.

http://dx.doi.org/10.1016/j.jnnfm.2012.09.010.

Sadeghy, K., Hajibeygi, H., and Taghavi, S.M., 2006, "Stagnation-Point Flow of Upper-Convected Maxwell Fluids," International Journal of
Non-Linear Mechanics, 41(10), 1242-1247.

http://dx.doi.org/10.1016/j.ijnonlinmec.2006.08.005.

Sadeghy, K., Najafi, A.H., and Saffaripour, M., 2005, "Sakiadis Flow of an Upper-Convected Maxwell Fluid," International Journal of NonLinear Mechanics, 40(9), 1220-1228.

http://dx.doi.org/10.1016/j.ijnonlinmec.2005.05.006.

Vajravelu, K., Prasad, K., Lee, J., Lee, C., Pop, I., and Van Gorder, R.A., 2011, "Convective Heat Transfer in the Flow of Viscous Ag-Water and $\mathrm{Cu}$-Water Nanofluids over a Stretching Surface," International Journal of Thermal Sciences, 50(5), 843-851.

http://dx.doi.org/10.1016/j.ijthermalsci.2011.01.008.

Yao, S., Fang, T., and Zhong, Y., 2011, "Heat Transfer of a Generalized Stretching/Shrinking Wall Problem with Convective Boundary Conditions," Communications in Nonlinear Science and Numerical Simulation, 16(2), 752-760.

http://dx.doi.org/10.1016/j.cnsns.2010.05.028. 